\title{
Why Do Nitrates Have Limited Efficacy in Coronary Microvessels?
}

\author{
Editorial to: "Lack of Nitrates on Exercise Stress Test Results in Patients \\ with Microvascular Angina" by G. Russo et al.
}

\author{
John F. Beltrame • John D. Horowitz
}

Published online: 22 March 2013

(C) Springer Science+Business Media New York 2013

The coronary circulation is unique since it is the only circulatory system that sustains its own existence by virtue of its mandatory role in cardiac viability and thus life. Similar to many regional circulations, its arterial system consists of large conduit vessels and the microcirculation, both of which can be afflicted by pathological states although most medical and revascularisation therapies primarily target the former.

\section{The Coronary Microvasculature — Not Just Smaller Vessels}

The coronary microcirculation differs both structurally and functionally to the large conduit arteries. Structurally, all of these vessels have an endothelium, media and adventitia but the microvessels have a well-developed vascular smooth muscle layer whereas the large vessels have more elastic properties for their conduit function. Functionally, the microvasculature differs both physiologically and pharmacologically to the large conduit arteries. Physiologically, the microvessels (especially the arterioles and pre-arterioles) are resistance vessels and the principal site for the regulation of coronary blood flow whereas the conduit vessels have limited impact on blood flow except in pathological states. Furthermore, the endothelial regulation of vascular tone in

\footnotetext{
J. F. Beltrame · J. D. Horowitz

Discipline of Medicine, University of Adelaide, Cardiology Unit, The Queen Elizabeth Hospital,

Adelaide, Australia

J. F. Beltrame $(\square)$

c/o TQEH Discipline of Medicine, Ward 5B, 28 Woodville Rd, Woodville South, SA 5011, Adelaide, Australia

e-mail: john.beltrame@adelaide.edu.au
}

these vessels differs with nitric oxide playing a greater role in the conduit vessels whereas endothelium-dependent hyperpolarising factor is more important in microvessels [1].

Pharmacological differences between these vessels are also evident; for example, there is heterogeneity in responses to calcium channel blockers (CCB). In large vessels the combined L/T-type CCB (mibefradil and efonidipine) have similar efficacy to the conventional L-type CCB (verapamil and nifedipine) in inhibiting vasoconstrictor responses, however in microvessels the L/T-type CCB are more potent than the conventional CCBs [2]. In part, this may be due to the greater prevalence of T-type calcium channels in the microvessels [2].

\section{Advances in Nitrate Pharmacology from Coronary Microvascular Disorders}

Medical science frequently advances from understanding pathological conditions, thus investigations into coronary microvascular disorders may provide further insights into the human coronary microvasculature. The challenge in investigating these disorders is the inability to directly visualise the microvasculature so that clinical studies require indirect measures of coronary microvascular dysfunction such as the presence of ischaemia or impaired coronary blood flow, both of which can be influenced by obstructive coronary artery disease. Accordingly, microvascular dysfunction must be evaluated in the absence of significant epicardial coronary artery disease even though large vessel and microvascular dysfunction can co-exist [3].

Cardiac syndrome $\mathrm{X}$ has been the most extensively studied coronary microvascular disorder and is conventionally defined by predominantly exertional angina, significant ST depression on exercise stress testing, normal coronary angiography, and the absence of other cardiac disorders. In 
this condition, beta blockers [4], calcium channel blockers [5], nicorandil [6], enalapril [7], and trimetazidine [8] have each been shown to be effective anti-ischaemic/anti-anginal therapies in randomised clinical trials whereas nitrates have only limited benefits [9].

In the current issue of Cardiovascular Drugs and Therapy, Russo et al. [10] further explored the role of nitrates in cardiac syndrome $\mathrm{X}$ patients by evaluating exercise-induced ischaemic ECG changes with/without low dose nitrates (5 mg sublingual isosorbide dinitrate), comparing these to stable angina patients who had single vessel disease. As in a previous study [9], they demonstrated an improvement in exercise-induced ischaemia with nitrate pre-treatment in half of the stable angina patients but in only 1 of the 29 syndrome $\mathrm{X}$ patients. Furthermore they demonstrated a blunted coronary blood flow response to $25 \mathrm{mcg}$ of sublingual nitroglycerine in the cardiac syndrome $\mathrm{X}$ patients compared to patients with single vessel disease, when blood flow was assessed in a vessel without an epicardial stenosis and thus reflective of microvascular function.

These findings have two important implications. Firstly consistent with previous literature, the microvascular disorder appears to be hypo-responsive to nitrates as compared with large vessel disorder in preventing exercise-induced ischaemia. Secondly, the blood flow responses suggest that the nitrate microvascular hypo-responsiveness is specific to syndrome $\mathrm{X}$ since the nitrate response is impaired relative to the microvascular (blood flow) responses in patients with obstructive coronary artery disease. Thus nitrate vasomotor responses may not only be blunted in microvessels compared with large vessels but especially within the microvessels of syndrome $\mathrm{X}$ patients.

It has long been appreciated that nitrates are potent vasodilators of large coronary vessels but that higher doses are required to alter coronary blood flow in the resting circulation, reflecting a reduced potency in microvessels [11]. This microvascular hypo-responsiveness to nitrates is reversed when nitroglycerine is administered with L-cysteine or $\mathrm{N}$-acetylcysteine [12], presumably by generating S-nitrocysteine. More recently, studies by Eaton and coworkers $[13,14]$ have established that the molecular 'targets' for organic nitrates are sensitive to changes in oxidative stress. In particular, protein kinase $\mathrm{G}$ becomes less sensitive to nitric oxide under increased redox stress, while responding more readily to other activators such as Snitrocysteine and hydrogen peroxide. The observation of tissue resistance to nitric oxide $[15,16]$, a common finding in association with redox stress, may therefore provide a potential pharmacological solution to microvascular nitrate hypo-responsiveness. Future therapeutic studies should explore this pharmacological target to improve the efficacy of nitrates in the coronary microvasculature, particularly in patients with syndrome X.

\section{References}

1. Shimokawa H, Yasutake H, Fujii K, Owada MK, Nakaike R, Fukumoto Y, et al. The importance of the hyperpolarizing mechanism increases as the vessel size decreases in endotheliumdependent relaxations in rat mesenteric circulation. J Cardiovasc Pharmacol. 1996;28:703-11.

2. Ball CJ, Wilson DP, Turner SP, Saint DA, Beltrame JF. Heterogeneity of 1 - and t-channels in the vasculature: rationale for the efficacy of combined 1- and t-blockade. Hypertension. 2009;53:654-60.

3. Beltrame JF, Crea F, Camici P. Advances in coronary microvascular dysfunction. Heart Lung Circ. 2009;18:19-27.

4. Lanza GA, Colonna G, Pasceri V, Maseri A. Atenolol versus amlodipine versus isosorbide-5-mononitrate on anginal symptoms in syndrome x. Am J Cardiol. 1999;84:854-6. A858.

5. Romeo F, Gaspardone A, Ciavolella M, Gioffre PA, Reale A. Verapamil versus acebutolol in syndrome x. Am J Cardiol. 1988;62:312-3.

6. Chen JW, Lee WL, Hsu NW, Lin SJ, Ting CT, Wang SP, et al. Effects of short-term treatment of nicorandil on exercise-induced myocardial ischemia and abnormal cardiac autonomic activity in microvascular angina. Am J Cardiol. 1997;80:32-8.

7. Kaski JC, Rosano GC, Gavrielides S, Chen L. Effects of angiotensin-converting enzyme inhibition on exercise-induced angina and st segment depression in patients with microvascular angina. J Am Coll Cardiol. 1994;23:652-7.

8. Nalbantgil S, Altintigbreve A, Yilmaz H, Nalbantgil II, Onder R. The effect of trimetazidine in the treatment of microvascular angina. Int J Angiol. 1999;8:40-3.

9. Lanza GA, Manzoli A, Bia E, Crea F, Maseri A. Acute effects of nitrates on exercise testing in patients with syndrome $\mathrm{x}$. Clinical and pathophysiological implications. Circulation. 1994;90:2695-700.

10. Russo G, Di Franco A, Lamendola P, Tarzia P, Nerla R, Stazi A, et al. Lack of effect of nitrates on exercise stress test results in patients with microvascular angina. Cardiovasc Drugs Ther. 2013;27: this issue

11. Abrams J. Hemodynamic effects of nitroglycerin and long-acting nitrates. Am Heart J. 1985;110:216-24.

12. Wheatley RM, Dockery SP, Kurz MA, Sayegh HS, Harrison DG. Interactions of nitroglycerin and sulfhydryl-donating compounds in coronary microvessels. Am J Physiol. 1994;266:291-7.

13. Burgoyne JR, Madhani M, Cuello F, Charles RL, Brennan JP, Schroder E, et al. Cysteine redox sensor in pkgia enables oxidant-induced activation. Science. 2007;317:1393-7.

14. Burgoyne JR, Prysyazhna O, Rudyk O, Eaton P. Cgmpdependent activation of protein kinase $\mathrm{g}$ precludes disulfide activation: implications for blood pressure control. Hypertension. 2012;60:1301-8.

15. Burgoyne JR, Mongue-Din H, Eaton P, Shah AM. Redox signaling in cardiac physiology and pathology. Circ Res. 2012;111:1091-106.

16. Willoughby SR, Rajendran S, Chan WP, Procter N, Leslie S, Liberts EA, et al. Ramipril sensitizes platelets to nitric oxide: implications for therapy in high-risk patients. J Am Coll Cardiol. 2012;60:887-94. 